\title{
Refining teacher design capacity: Mathematics teachers' interactions with digital curriculum resources
}

\author{
B. Pepin ${ }^{1} \cdot$ G. Gueudet ${ }^{2} \cdot$ L. Trouche ${ }^{3}$
}

Accepted: 31 May 2017 / Published online: 9 June 2017

(C) The Author(s) 2017. This article is an open access publication

\begin{abstract}
The goal of this conceptual paper is to develop enhanced understandings of mathematics teacher design and design capacity when interacting with digital curriculum resources. We argue that digital resources in particular offer incentives and increasing opportunities for mathematics teachers' design, both individually and in collectives. Indeed they require increased design expertise because of the changing nature of the resources. Drawing on the literature (1) we suggest ten questions providing a tool to study teacher design processes; and (2) we propose three components for exploring teacher design capacity. Building on two main theoretical areas (i.e. teaching as design; documentational approach to didactics) we propose to deepen understandings of the notions of "teacher design" and "teacher design capacity". Drawing on two different collective environments and two individual teacher cases working within these environments, we investigate and illustrate teachers' design processes and design capacity building across a range of contexts and curriculum formations, with the focus on how digital resources can help to develop teacher design capacity. We claim that the evolutions of digital resources in particular require an elaboration and
\end{abstract}

\footnotetext{
B. Pepin

b.e.u.pepin@tue.nl

G. Gueudet

ghislaine.gueudet.@espe-bretagne.fr

L. Trouche

luc.trouche@ens-lyon.fr

1 Eindhoven School of Education, Eindhoven University of Technology, Eindhoven, The Netherlands

2 CREAD, University of Brest, Brest, France

3 French Institute of Education, Ecole Normale Supérieure de Lyon, Lyon, France
}

refinement of the concept of teacher design capacity, which we develop and illustrate. Indeed, interacting with digital resources, it is claimed, might be a fruitful vehicle for developing teachers' design capacity, in particular when working in collectives.

Keywords Mathematics teachers - Teacher design . Digital curriculum resources · e-Textbooks · Teacher design capacity

\section{Introduction}

Internationally, much research in mathematics education has focused on teachers' interactions with and use of curriculum resources (e.g., Pepin et al. 2013; Remillard 2005; Remillard et al. 2008). At the same time, a shift from textbased to digital interactive school curriculum materials is providing teachers with more interactive materials, and hence has the potential to transform educational processes and bring about new educational dynamics (Pepin et al. 2015). Moreover, there is evidence that in selected countries (e.g., France; The Netherlands; UK; USA) the design, selection and implementation of e-resources are increasingly driven by practicing teachers (Gueudet et al. 2016), with an expanding market and provision of resources available on the Internet. However, little is known about the impact of such shifts on mathematics teachers' work.

Whilst previously teachers were typically seen as the 'implementers' of curriculum materials, which had been developed by professional curriculum designers and mathematicians, now mathematics teachers have become 'designers', or act as 'partners' in the design of curriculum materials (Jones and Pepin 2016). It is recognized that when teachers interact with curriculum resources, they develop 
curriculum expertise, individually when preparing their lessons, and collectively in professional development sessions and other interactions with their colleagues (e.g., Pepin et al. 2016). Moreover, the collective dimension is an important aspect of teachers' professional development and capacity building (e.g., Jaworski 2001).

The aim of this paper is to develop further insights into mathematics teacher expertise (Pepin et al. 2016), focusing on their interactions with digital curriculum resources. We argue that, with a wave of new digital curriculum resources, design has become, more than before, a crucial aspect of teachers' work. Our argument is that digital resources in particular (including e-textbooks) offer incentives and increasing opportunities for mathematics teachers' design, both individually and in collectives. Indeed they require increased design expertise because of the changing nature of the resources. Thus, it is essential to deepen our understandings of mathematics teacher design and teacher design capacity (within the large area of teacher expertise). We claim that the evolutions of digital resources in particular require an elaboration and refinement of the concept of teacher design capacity, which we develop and illustrate, based on our findings from two different environments and studies.

Our research question is the following:

How can teachers' interactions with resources be understood in terms of teacher design and teacher design capacity building, in particular those that are linked to digital resources?

The research is anchored in two purposefully selected environments, which illustrate both (a) collective and (b) individual design processes:

- First environment (a) The collective design processes of selected teachers of the French Sésamath association for the design of a grade 10 e-textbook (see Gueudet et al. 2016), linked to (b) the investigation of Vera's design/s, as she engages with digital resources in the preparation of/for her teaching, in particular with Sésamath resources;

- Second environment (a) The promoting inquiry-based learning in Mathematics and Science across EuropePRIMAS (see Sikko et al. 2012) project in Norway, linked to (b) the investigation of a Norwegian teacher, Cora, as she interacts with digital (and traditional) PRIMAS resources.

After this introduction, in the subsequent (second) section we discuss the relevant literature and theoretical frames, in particular in relation to the following: teacher interaction with resources; the notions of documentation; teaching as design; and design capacity. In the third section, the two environments and associated studies of teacher interaction with resources are described and analyzed with respect to the two analytical frames of teacher design and teacher design capacity. In the fourth section, we answer the research questions and draw our conclusions in terms of what we claim to have added to the understanding of teacher design and teacher design capacity.

\section{Literature background and theoretical frames}

\subsection{Teacher interaction with traditional and digital curriculum resources}

Teachers design and interact with curriculum resources to prepare and set up their teaching in class; they also work with colleagues in school, or across schools in local, regional or international professional development collectives, to design and adapt curriculum materials for their own teaching and that of their colleagues. In an earlier issue of ZDM (see Pepin et al. 2013), we argued that different processes are at stake in this work and interaction with curriculum materials, both individually and collectively.

In this paper we build on this earlier work. With digital resources, however, one could anticipate that these processes are likely to change: for example, one could expect that digital resources introduce new possibilities for 'transformation' (e.g., videos might provide opportunities for innovative practices), and Choppin et al. (2014) claim that "digital platforms have been characterized as potentially transformative" (p. 11). Their analyses of particular United States programs led them to observe, however, that the programs analyzed apparently offered "few changes to the underlying opportunities for teaching and learning found in print materials", and "the use of multimedia in particular lacked interactivity." This rings true for our research on e-textbooks (e.g., Gueudet et al. 2017; Pepin et al. 2016), where we observed that more connections of different kinds could be made in existing e-textbooks.

In the following subsections we propose two theoretical frames that model teachers' interactions with resources, i.e. the documentation approach, and 'teaching as design'; and we subsequently identify components that are likely to help us analyse and understand teacher design capacity.

\subsection{The documentational approach to didactics}

The documentational approach to didactics (Gueudet et al. 2012), acknowledges the central role of resources for teachers' work. The understanding of a resource in this approach is anchored in Adler's (2000) work, which defines a resource as anything likely to "re-source" the teacher's work. A textbook or any curriculum material is naturally a 
resource; a discussion with a colleague, or students' work, can also constitute resources for the teacher. The documentational approach maintains two main concepts introduced by Verillon and Rabardel (1995) (as in the instrumentation approach-see Trouche 2004): instrumentation; instrumentalisation. For performing a teaching task, a teacher interacts with a set of resources. This interaction combines two interrelated processes: first, the process of instrumentation, where the selected resources support and influence the teacher's activity, and which can be linked to Brown's (2009) characteristics of curriculum materials, i.e. that they represent an interface between the knowledge, goals, and values of the author and the user. Second, there is the process of instrumentalisation, where the teacher adapts the resources for his/her needs, which can also be linked to Brown's (2009) characteristics, i.e., that curriculum materials require craft in their use; they are inert objects that come alive only through interpretation and use by a practitioner.

This productive interaction between an individual teacher, or a group of teachers, and a set of resources, guided by a teaching goal, through successive stages of (re-) design and implementation in class, gives birth to a hybrid entity, a document: this consists of the resources adapted and re-combined; and the ways the teacher uses them ("usage scheme/s" according to Vergnaud 2013), which include the stable organizations of associated activities and particular usages, and contain the 'knowledge' guiding the usages.

The different documents developed by a teacher are not isolated, but organized in a structured system. This system encompasses resources and 'usage schemes'; and the resources part constitutes the teacher's resource system. The documentational approach to didactics has developed specific methods for analyzing a teacher's resource system, particularly the Schematic Representation of a teacher's Resource System (SRRS-see Gueudet et al. 2013), in which a teacher is asked to draw his/her resources and the locations of and connections between those resources (see Figs. 1, 2 in the findings section).

\subsection{Teaching as design}

To view teachers' use of curriculum resources as a design activity is not a new idea. As Brown (2009) explains, "teachers must perceive and interpret existing resources, evaluate the constraints of the classroom setting, balance tradeoffs, and devise strategies-all in the pursuit of their instructional goals" (p. 18). He claims that the interpretation of teaching as design, and the notion of teachers as designers, is fitting with a range of cognitive theories that "emphasize the vital partnership that exists between individuals and the tools they use to accomplish their goals. ... And it is not just the capacities of individuals that dictate human accomplishment, but also the affordances of the artifacts they use" (p. 19).

We concur with Brown (2009), as we understand his notion of design, to regard "design" as the practice of designing for teaching, as in lesson preparation (that is design before enactment), as well as in teaching, what we labeled as "design-in-use" that happens during enactment of the resources/materials (e.g., Pepin et al. 2013). For example, when a teacher is marking students' work, we consider that this is not design work. It can nevertheless influence further design, in particular the design of assessment tasks. To elaborate, we understand that teacher design can be described as the creation of 'something new' (e.g., combining existing and novel elements) as a deliberate/conscious act in order to reach a certain (didactical) aim.

At the same time "instructional design" is defined as the practice of creating "instructional experiences which make the acquisition of knowledge and skill more efficient, effective, and appealing." (Wikipedia, ${ }^{1}$ 29th January 2017). This is helpful, in particular as we want to develop an analytical framework based on ideas of "design" (for developing a deeper understanding of teacher design), in order to better understand, and potentially enhance, mathematics teacher design approaches in practice.

Curriculum theory highlights research in curriculum design (e.g., van den Akker 2003) and teachers' work as designers (e.g., Nieveen and van der Hoeven 2011). This literature suggests ten questions to study "curriculum design" for student learning. For our purpose we have amended these questions, to investigate "teacher design":

Q1 Why are teachers designing?-e.g., dissatisfaction with textbook; to become less dependent on the textbook; to make teaching more varied;

Q2 What are their aims and goals?-e.g., to prepare a series of exemplary lessons for particular topic areas;

Q3 What is the audience?-e.g., fellow teachers; teachers nationwide; students;

Q4 What are they designing?-e.g., lessons; assessment questions;

Q5 How are they designing?-e.g., design approaches; sequences; strategies; styles;

Q6 What are the resources and tools used for the design?-e.g., resources used;

Q7 With whom are they designing?-e.g., in a group; individually; team membership;

Q8 Where are they designing?-e.g., in school; on the Internet - the design environment;

Q9 When are they designing?-e.g., how long does the design take;

\footnotetext{
${ }^{1}$ https://en.wikipedia.org/wiki/Design.
} 
Q10 How is the design evaluated-e.g., expert appraisal; peer appraisal; observation/interviews of/with users; assessing learning results.

This frame is helpful for comparing teacher design, in particular when we compare collective and individual aspects of teacher design.

\subsection{Teacher design capacity}

In mathematics and science education, according to Brown (2009) teachers' pedagogical design capacity (PDC) is the capacity to utilize and transform existing curricular resources effectively, and to design/create new materials, for the purpose of effective mathematics instruction. He identified three types of curriculum use: offloading, adapting, and improvising, and proposed a framework for describing teachers' capacity to design with curriculum materials (Design Capacity for Enactment Framework). Brown (2009) describes a spectrum: from offloading when teachers follow curriculum materials closely, over adapting when teachers modify their materials to support instructional goals, to improvising when teachers craft instruction spontaneously and/or without specific guidance from their materials.

In Brown's words, PDC represents "a teacher's skill in perceiving affordances, making decisions, and following through plans" (p. 29), regardless of whether such decisions manifest as offloads, adaptations, or improvisations. He explains that it is "the skill in weaving various modes of use together and in arranging the various pieces of the classroom setting that is the mark of a teacher with high PDC. ... PDC describes the manner and degree to which teachers create deliberate, productive designs that help accomplish their instructional goals" (p. 29). Hence, whilst acknowledging the influence of curriculum materials on teachers' practice and decision-making, Brown notes the importance of understanding the "dynamic and constructive ways" (p. 22) teachers interpret and use curriculum materials. Interestingly, in particular from the theoretical viewpoint, the framework integrates the analysis of curriculum resources in view of the literature on the mediating role of artifacts (e.g., Wartofsky 1973), and teacher resources in terms of subject matter knowledge, pedagogical content knowledge, and commitments that influence teacher design capacity.

In the curriculum field the expertise required to design and enact the curriculum has been described by various scholars (e.g., Nieveen and van der Hoeven 2011; Huizinga 2009). They use different labels to describe elements of the same concept, including curriculum design competencies; instructional design competencies; and design expertise. For Huizinga (2009), design expertise consists of three aspects (curriculum design expertise; subject matter knowledge; pedagogical content knowledge), and it includes analysis, design, development, implementation and evaluation skills. Huizinga (2009) distinguishes between generic design and process expertise (knowledge and skills for enacting design processes in general) and specific design expertise (knowledge and skills for developing curricula/lesson series). The latter would include content knowledge, pedagogical content knowledge, and curriculum consistency expertise (knowledge and skills to create internally and externally consistent curricula). Moreover, Huizinga et al. (2015) identified three specific activities that seemed to offer opportunities for developing teachers' curriculum design expertise: (1) the use of exemplary materials; (2) evaluating the designed materials; and (3) sharing experiences of the conducted design process.

Leaning on these two bodies of literature we define teacher design capacity to include the following components (which we illustrate, and sharpen up, with the help of the empirical cases in the subsequent sections):

- An orientation, a goal, or point/s of reference for the design:

- To know the "status quo" (e.g., what do students know, which problems they do have in terms of misconceptions), as well as where she/he is heading in terms of her/his mathematical-didactical design;

- To understand the larger (e.g. national curriculum guidelines) and the smaller picture (e.g. learning trajectory for a particular mathematical topic) of his/her design with respect to the curriculum (e.g., a task/ activity; a lesson; a lesson sequence; a departmental format of work for all pupils of a particular grade);

- To discern where it fits in the short (i.e. for a lesson cycle) as well as the long term (i.e. connecting topic areas across grades).

- A set of design principles, which must be firm but flexible: a teacher needs a set of 'universals' for the design, or principles, which are evidence-informed (e.g., from own practice) and supported by justification for their choices. We call those robust principles. At the same time these principles must be flexible enough, i.e., didactically flexible, to adapt to new challenges and contexts, so that the teacher's frame of reference can grow and expand, perhaps cover new areas, or differentiate/validate within the existing frame.

- "Reflection-in-action" type of implicit understandings and realizations: a teacher needs to be able to gener- 
ate relationships or informed potential lines of action, which are often not observable and which develop in the course of instruction (see earlier 'design-in-use').

What is clear from these theoretical frames is that teacher interaction with curriculum resources, whether digital or traditional, is a participatory two-way process of mutual adaptation (see the distinction between instrumentation and instrumentalisation earlier). Concerning the notions of teacher design and teacher design capacity, we have investigated these notions drawing on two different bodies of research literature (i.e. curriculum literature, and mathematics (and science) education literature). We now use the two environments and case studies as illustrations, and to explore and sharpen up the two notions.

\section{The two design environments and associated studies}

In this section we present a description of each study in addition to their analyses with respect to (1) teacher design; and (2) teacher design capacity (and its development) with the frames we developed in the previous section. The two environments and linked teacher studies were purposefully chosen, because they represented the following:

- The environment and collective design processes of a group of mathematics teachers designing an e-textbook chapter (on functions) for the wider mathematics education community (see Gueudet et al. 2016), the Sésamath community $^{2}$ in France; linked to this we present a study of an individual mathematics teacher's (Vera's) interaction with digital (and traditional) curriculum materials in/for her own classroom instruction;

- The environment and collective design processes of a group of designers (including researchers and teacher educators) of a European Union project, PRIMAS ${ }^{3}$; linked to this we present a study of an individual mathematics teacher's (Cora's) interactions with digital (and traditional) curriculum materials (designed by the PRIMAS project) in Norway, for her own classroom instruction and for working with colleagues in terms of professional development.

We would like to emphasize that this is not an international comparative study (comparing French and Norwegian teachers or projects). Rather, we purposefully

\footnotetext{
2 http://www.sesamath.net/.

${ }^{3}$ http://www.primas-project.eu/en/index.do.
}

selected these studies and teachers, because they illustrated mathematics teacher/s interacting with resources in different situations: collective design and individual design in both cases; moreover the collective design (of Sésamath) was aimed at teachers' individual use in/for their teaching, whereas the collective design of PRIMAS modules and tasks was explicitly aimed at mathematics and science teacher professional development. We hypothesized that these situations would provide diverse opportunities for studying the two notions.

\subsection{First study: the Sésamath association, and an individual teacher using Sésamath resources}

\subsubsection{Collective design work: Sésamath}

Sésamath is an association of secondary school mathematics teachers in France, created in 2001. It designs and freely offers on its website a variety of teaching resources: interactive exercises for grades 5-10 (Mathenpoche), software, e-textbooks for grades 6-12, and even a complete virtual environment, LaboMEP, allowing the teacher to associate all these kinds of resources. We have followed in particular the design by a team of secondary school teachers of the Sésamath grade 10 e-textbook (Sabra and Trouche 2011; Gueudet et al. 2016), which took place from June 2009 to December 2013.

For the design they used a collaborative platform and a mailing list. For our study we collected the following data: the discussions on the platform; the resources exchanged on the platform; and an agenda of follow-up (filled in by two members of the group). Through this agenda, these members were actively connected with the work. The different features of their design work are presented in Table 1.

\subsubsection{Individual design work: Vera}

Vera is a 40-year-old teacher. For 4 years she has taught at a lower secondary school. We have chosen to analyze Vera's documentation work of a new lesson: it was the first time that Vera taught a grade 8 class (but she had experience with grade 7 classes). We chose a lesson about percentages, because of the diversity of resources that could be mobilized for such a purpose, including the Sésamath resources, and the new curriculum insisting on using resources drawing on 'real life' situations.

We focused on a lesson cycle comprising of four 'moments': lesson preparation (evidence: interview); enactment of the lesson (evidence: video observations); evaluation of students' understanding (evidence: debriefing interview); and reflection (evidence: stimulated recall interview). The choice of such a lesson cycle is in line with the ideas underpinning the documentational approach (e.g., 


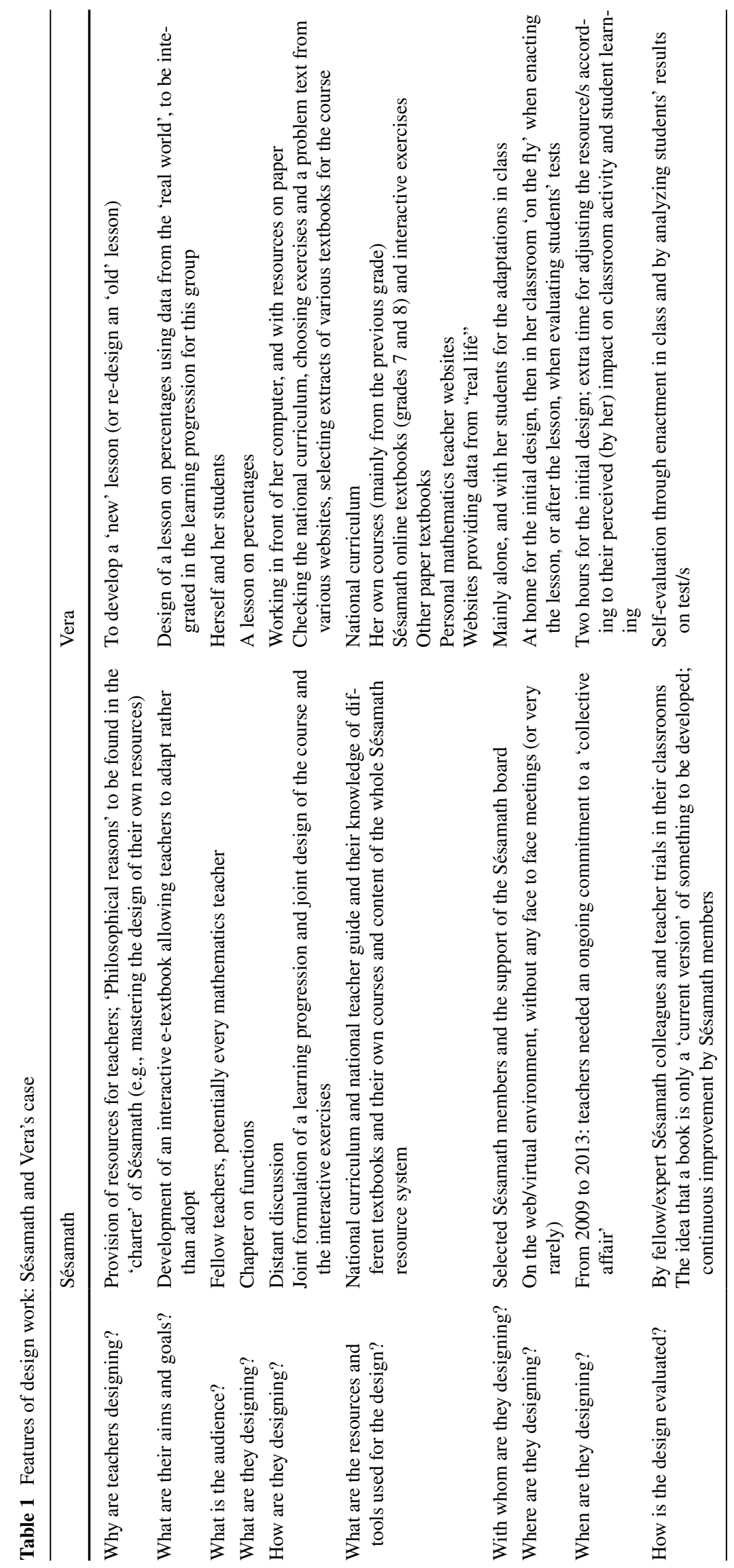


Gueudet et al. 2012): the design was not restricted to the initial design of a given resource for teaching a particular content, but continued during the course of using the resource. These four moments were video-recorded. The design work of Vera is presented in Table 1, and the analysis of her design capacity in the next subsection.

\subsubsection{Features of the design work and comparison}

Table 1 shows that the design works of both Sésamath and Vera were very rich, drawing on many different resources, in particular digital resources. Investigating the design processes also revealed that teachers' beliefs and convictions, and their goals, directed their documentation work: e.g., the Sésamath members were convinced that a textbook must have the potential to be adapted by its users, and digital resources were perceived to be particularly suitable for this; Vera was convinced that an introductory lesson must draw on a 'real-life' situation.

In terms of the evaluation of the resources designed and with whom, the Sésamath situation seemed much richer at first sight: the design was collective using a distant platform, and the evaluation was also done by a large group of teachers, members of the authors' group and also teachers using Sésamath resources and posting comments in the forum. Nevertheless, in the case of Vera the students participated in the design in class: if Vera observed that there was a problem with a given exercise in class, for example, she would amend or suppress it. In the case of Sésamath, the teachers observing difficulties when they used a resource would need to communicate it to the group of authors, and a new discussion would have to take place before the resource could be modified.

\subsubsection{Analysis of Vera's development of design capacity}

Observing Vera's lesson preparation and her work in class, we noticed a diversification and structuring of the resources feeding her design work: the abundance of available resources led her to organize them on her computer, mainly as a list of websites (e.g., institutional websites, websites for 'real-life mathematics'). We observed (Table 2) different dimensions of her design capacity, and the development of these dimensions:

1. Vera's goal was to design and set up a new learning progression on percentages, and her points of reference were provided by the French national curriculum framework (in particular in terms of content).

2. Vera had 'robust principles' for the design of a lesson, and these principles could be identified in the design of this new lesson on percentages. For example, she declared in the interviews that a new lesson should start with easy exercises, recalling students' previous knowledge; and that introductory problems should be connected with real-life situations.

3. Following her previous use of LaboMEP, Vera developed new design principles during the preparation of this lesson. She explained that since LaboMEP allowed her to propose different exercises to different students, it made her aware of the need to differentiate her teaching. LaboMEP also proposed variations of exercises with the same structure. Vera declared that it was a strong motivation for her to enhance her teaching, by mastering not only a set of familiar exercises but also those variations (with the same mathematical structure) related to a particular lesson. We contend that these new principles evidenced didactical flexibility.

4. Lesson observations of Vera's lesson/s evidenced reflection-in-action: During the percentage lesson/s she developed an increased awareness and knowledge of students' own work. Vera prepared and projected a 'written trace' on the IWB (synthetizing the main results and methods); this allowed her to freely circulate in the class, to check students' (written) work, and

Table 2 Examples of components of Vera's design capacity

\begin{tabular}{|c|c|}
\hline Components of design capacity (examples) & Vera \\
\hline Goal, point/s of reference & $\begin{array}{l}\text { To design and set up a new learning progression (e.g., on percentages) based on the } \\
\text { French national curriculum }\end{array}$ \\
\hline Set of design principles: example/s of robust principles & $\begin{array}{l}\text { Management of the class heterogeneity by proposing different exercises to different } \\
\text { students } \\
\text { Start with easy exercises making an explicit link with the previous lesson } \\
\text { Use of situations from the 'real world' }\end{array}$ \\
\hline Set of design principles: example/s of didactical flexibility & $\begin{array}{l}\text { Propose different exercises to different students } \\
\text { Propose different variations of a given exercises with the same structure }\end{array}$ \\
\hline 'Reflection in action': example/s & $\begin{array}{l}\text { Vera prepared and used a 'written trace' (synthesis of main results and methods) in } \\
\text { her lesson/s: she projected an initial version on the interactive whiteboard (IWB), } \\
\text { so she was able to observe the students' difficulties and produce a new version of } \\
\text { the written trace }\end{array}$ \\
\hline
\end{tabular}


to identify their misconceptions and difficulties. This kind of feedback led her to adapt her written trace in action, to better fit her students' needs.

\subsection{Second study: the case of PRIMAS, and an individual teacher using PRIMAS resources}

\subsubsection{Collective design work: PRIMAS}

The European PRIMAS project was a teacher professional development project running over four years (Jan 2010-Dec 2013). The project's aim was to change practices in the teaching and learning of mathematics and science at school, in the sense that mathematics and science teachers were supported in teaching in accordance with inquirybased learning (IBL) pedagogies (so that their students could gain experience of inquiry). The project brought together 13 teams of experts in mathematics and science education from 12 nations, amongst them the Norwegian team. During the project's lifetime, the project partners educated over 350 lead teachers in school ('multipliers'), around 2800 in-service teachers and more than 4200 preservice teachers. The Norwegian teacher/s whose work we have investigated for this study participated in the PRIMAS project.

The general strategy of the PRIMAS project for scaling up professional development of mathematics and science teachers was to educate multipliers who in turn would be expected to work with their colleagues. Our chosen teacher, Cora, was working in the context of the PRIMAS project: that is, Cora participated at university sessions (over 18 months) to become a multiplier, and she worked in turn with other colleagues in her school (and neighboring schools).

In the PRIMAS project resources corresponded to the following: (1) mathematics and science tasks; and (2) modules developed for teacher professional development sessions. All resources were developed by 'designers', i.e. academics working at the universities of the partner teams. These materials were provided, so that multipliers had materials for use in their own classrooms, to trial out, and for sessions with their colleagues.

\subsubsection{Individual design work: Cora}

For this paper we report on (1) Cora's general use of the PRIMAS modules (interview; Schematic Representation of Cora's Resource System); and (2) her adaptation and use of a particular PRIMAS module and associated tasks on 'division of fractions' (lesson preparation; video observation; interview). All modules were provided digitally, so that multipliers and teachers could amend the modules and tasks in the modules for/in their instruction.

For several years Cora had been working in the same primary school (grades 1-7). After joining the PRIMAS project, Cora worked as a multiplier in her school. She worked closely with other colleagues, including grade coordinators and her mathematics/science colleagues.

For the lesson on 'division of fractions' Cora developed a detailed lesson plan based on the PRIMAS module (in fact she used the PRIMAS word file from the website), and she used a PRIMAS worksheet, which had been amended by Cora according to the Norwegian context (e.g., "Katrina is cooking" was changed to "Katrine prepares jam"a common activity in Norwegian homes). The lesson plan included the following:

- Pupils' previous knowledge;

- Aim/s of the lesson;

- A detailed 'what will happen' list, including activities, questions (asked by the teacher) and organization of pupils (e.g., in groups), and

- An evaluation.

In the module it was suggested that the teacher would play 'diverse roles' in different parts of the activity, and indeed Cora had purposefully selected some (e.g., using her 'good questioning' techniques developed in earlier modules). In the follow-up interview (after her enactment of the lesson) she showed us the worksheets with pupils' written work, and she assessed how certain parts (in particular the group work, and plenary session) had worked out according to her goals, in particular with respect to her perception of good questioning (Table 3).

\subsubsection{Features of the design work and comparison}

The PRIMAS modules and tasks were all in digital format designed by academic and professional designers working at the different countries' universities and participating in the PRIMAS project teams, and the audience was the PRIMAS multipliers and local teachers. These modules and tasks were purposefully and 'flexibly' designed (in terms of adaptability), so that teacher educators could amend them and work with multipliers, and teachers could adapt and trial out the tasks in their classes. At the same time Cora's design activities mainly included the amendment and redesign of the tasks, and aligning her lesson plans with the aims of the PRIMAS module. In terms of audience, her (re-) design would often involve the 'mediation' of the PRIMAS aims and tasks for her colleague teacher audience, or indeed her students in school. 
Table 3 Features of design work: PRIMAS and Cora's case

\begin{tabular}{|c|c|c|}
\hline & PRIMAS (team) & Cora (and her colleagues) \\
\hline Why are teachers designing? & $\begin{array}{l}\text { To support teachers in integrating and applying IBL } \\
\text { pedagogies in their classrooms }\end{array}$ & $\begin{array}{l}\text { For her own instruction, and for her work with col- } \\
\text { leagues }\end{array}$ \\
\hline What are their aims and goals? & $\begin{array}{l}\text { Design of teaching resources freely available on the } \\
\text { web, to effect change across Europe in the teaching } \\
\text { and learning of mathematics/science with respect } \\
\text { to IBL }\end{array}$ & $\begin{array}{l}\text { To enhance/develop her teaching, so that students gain } \\
\text { first-hand experience of scientific inquiry }\end{array}$ \\
\hline What is the audience? & Multipliers and teacher educators & $\begin{array}{l}\text { Colleague teachers } \\
\text { Students }\end{array}$ \\
\hline What are they designing? & $\begin{array}{l}\text { Teaching materials (tasks) } \\
\text { Professional Development (PD) modules }\end{array}$ & $\begin{array}{l}\text { Adaptation of the task/s for her own lessons } \\
\text { Amendment of the PD modules for work with col- } \\
\text { leagues }\end{array}$ \\
\hline How are they designing? & $\begin{array}{l}\text { Team of authors: university teacher educators and } \\
\text { specialist designers }\end{array}$ & $\begin{array}{l}\text { In PD sessions (work with colleagues) } \\
\text { On her own }\end{array}$ \\
\hline $\begin{array}{l}\text { What are the resources and } \\
\text { tools used for the design? }\end{array}$ & $\begin{array}{l}\text { Research literature } \\
\text { Designers' experience and knowledge }\end{array}$ & $\begin{array}{l}\text { Adaptation of PRIMAS materials with materials such } \\
\text { as: Cora's own course materials (and those of her } \\
\text { colleagues) } \\
\text { Norwegian National Curriculum } \\
\text { Norwegian textbooks }\end{array}$ \\
\hline With whom are they designing? & $\begin{array}{l}\text { Correspondence with local specialists at university } \\
\text { and European colleagues }\end{array}$ & $\begin{array}{l}\text { With colleagues } \\
\text { On her own }\end{array}$ \\
\hline Where are they designing? & $\begin{array}{l}\text { At university/place of work, testing with local teach- } \\
\text { ers and sharing on the PRIMAS website }\end{array}$ & $\begin{array}{l}\text { In PD sessions } \\
\text { At home or in school }\end{array}$ \\
\hline When are they designing? & Several years & $\begin{array}{l}\text { During the PD sessions and at home, or in discussion } \\
\text { with colleagues }\end{array}$ \\
\hline How is the design evaluated? & $\begin{array}{l}\text { Evaluation during PD sessions and by PRIMAS } \\
\text { users/teachers } \\
\text { Evaluation by designated PRIMAS evaluation }\end{array}$ & By teachers and multiplier/s in their PD sessions \\
\hline
\end{tabular}

\subsubsection{Analysis of Cora's development of design capacity}

In interviews Cora made clear that she highly appreciated the 'exemplary' materials, in particular the PRIMAS modules and associated tasks, and she also spoke of the appreciation of her colleagues. Using the specially prepared materials apparently helped her not only to enhance her IBL practices, but also to reflect on (and in turn design for) related themes (e.g., 'questioning' and other formative assessment practices). Using the PRIMAS materials seemed to have improved her (and her colleagues') understandings of how to translate IBL (and related) ideas to curriculum materials, often redesigning and translating (on the template) the digital materials provided. It appeared that the exemplary materials helped the design process, as the materials provided inspiration for and insights into potentially learning enhancing designs. In addition, as the materials came from university institutions, it was assumed that they were of good didactical quality and research-based (in comparison with selected web-based materials she had tried before). Furthermore, discussing and evaluating materials (e.g., in practice in class, and with her colleagues in feedback sessions) helped her to develop agency and feel that she had used her creativity in the (re-) design process, which gave her confidence. The collegial feedback sessions were valuable, Cora said, as they offered opportunities for team discussions on how to improve the materials and they had a clear purpose.

We observed different dimensions of her design capacity, and the development of these dimensions (see Table 4):

1. Cora's goal for her design was to enhance/develop her teaching, so that students gain first-hand experience of scientific inquiry, and her points of reference were clearly anchored in (a) the Norwegian national curriculum/chosen textbook, and (b) the PRIMAS guidelines. Comparing her SRRS's at two data points (see Figs. 1, 2 ), whereas early in her course her resource system was relatively 'simple' and unstructured (outlining selected human resources, e.g., parents, pupils, colleagues) and websites (e.g., enrich website; matematikk.org; PRIMAS), after the PRIMAS course she had developed a more sophisticated system of resources, with arrows clearly indicating her aims and directions concerning how to prepare for her teaching. She also included more websites and articles for preparing her 'new self- 
Table 4 Examples of components of Cora's design capacity

\begin{tabular}{|c|c|}
\hline Components of design capacity (examples) & Cora \\
\hline Goal, point/s of reference: examples & $\begin{array}{l}\text { To improve her teaching with IBL pedagogies, also with reference to the Norwegian } \\
\text { national curriculum guidelines/the textbook and PRIMAS guidelines }\end{array}$ \\
\hline Set of design principles: example/s of robust principles & $\begin{array}{l}\text { Listening carefully to pupils and building her lessons around pupil thinking } \\
\text { IBL principles; formative assessment principles } \\
\text { Principles of good questioning (as part of formative assessment practices) }\end{array}$ \\
\hline Set of design principles: example/s of didactical flexibility & $\begin{array}{l}\text { Application of 'questioning' principles to different topic areas in mathematics and } \\
\text { science } \\
\text { Differentiating tasks for different audiences (e.g., slow learners) and with different } \\
\text { resources (e.g., particular equipment, such as GeoGebra, or manipulatives—see } \\
\text { Cora's drawings) }\end{array}$ \\
\hline 'Reflection in action': example/s & $\begin{array}{l}\text { Responding to pupils in ways that helps them to progress (using formative assess- } \\
\text { ment strategies during group work) }\end{array}$ \\
\hline
\end{tabular}

made activity or task' (see Fig. 2), and for work with the smart board.

2. In terms of robust design principles, she declared (after PRIMAS) that she would build her lessons around pupil thinking (rather than content related), and she emphasized selected formative assessment principles. It appeared that the PRIMAS course and the work with the digital resources in PRIMAS had given her new inspiration and directions for teaching (and preparing for teaching) in the ways she appreciated. This was particularly evident in her 'questioning' techniques, which by the end of the course appeared to be robust and confidently developed. In the final interview Cora was clear that she now listened carefully to her pupils and built her lessons around their thinking-a robust principle that developed over time.

3. In terms of didactical flexibility Cora mentioned her increasing confidence with regard to differentiating tasks for different audiences (e.g., slow learners) with different resources (e.g., particular equipment, such as GeoGebra, see Fig. 2). She also said that she now applied her acquired questioning techniques (e.g., digital worksheets she had prepared for her work with colleagues) to different mathematical topic areas. We claim that her didactical flexibility had clearly increased, evidenced by the structured way she explained the different resources, their use and the connections between the resources.

4. In terms of 'reflection-in-action', Cora used her developed formative assessment strategies to help pupils to progress during group work: for example, she refused to directly answer pupils' questions, but rather posed more questions that she regarded as helpful for their developing thinking.

In addition, we can also illustrate her development in terms of design capacity with her drawings (Figs. 1,2) at the start of her involvement with, and after the PRIMAS course. Comparing the two drawings, and from the interviews based on the drawings, we can see that Cora added new structures to her teaching repertoire: e.g., the "tenkestarter" (thinking starters), which she typically used in the first $5 \mathrm{~min}$ of her lessons. These were often developed from the national tests, or from the textbook, and often projected on the board. In order to prepare these, she said, she would read about misconceptions, and listen and think about students' answers. She also included the "matterom" (mathematics room) in her drawings: this was a national initiative, to provide every school with materials (e.g., concretes/manipulatives; selected software) for the mathematics lessons, and it became one of her tasks in the school to provide her colleagues with inspiration for using this equipment meaningfully; this she managed with the help of the PRIMAS modules and tasks. An interesting development was also visible (on the left hand side of the drawing), when Cora explained the development of her documents: starting with the national curriculum, to the "arsplan" (yearly syllabus), to the "ukeplan" (weekly plan), and connecting to websites such as NRich, which would then feed into her selection of activities and tasks prepared for her lessons, which would subsequently be amended according to students' responses. When asking Cora about her own perception of her competence development over time, what she regarded as the 'residue', she was clear that (rather than preparing her lessons according to other people's principles, or textbook guidelines) she would now 'listen' to her pupils in ways that would subsequently inform her lesson preparations, selection of tasks, and 'in-the-moment' decisions. 
Fig. 1 Cora's SRRS in April 2012

Fig. 2 Cora's SRRS in February 2015

\section{Discussion of results}

In this section we draw on our empirical cases, in order to investigate and illustrate facets of teacher design and design capacity development that we could identify in our data. We firstly discuss the results on design, and subsequently focus on design capacity. In each case we emphasize the specific features linked with digital resources (see the research question).
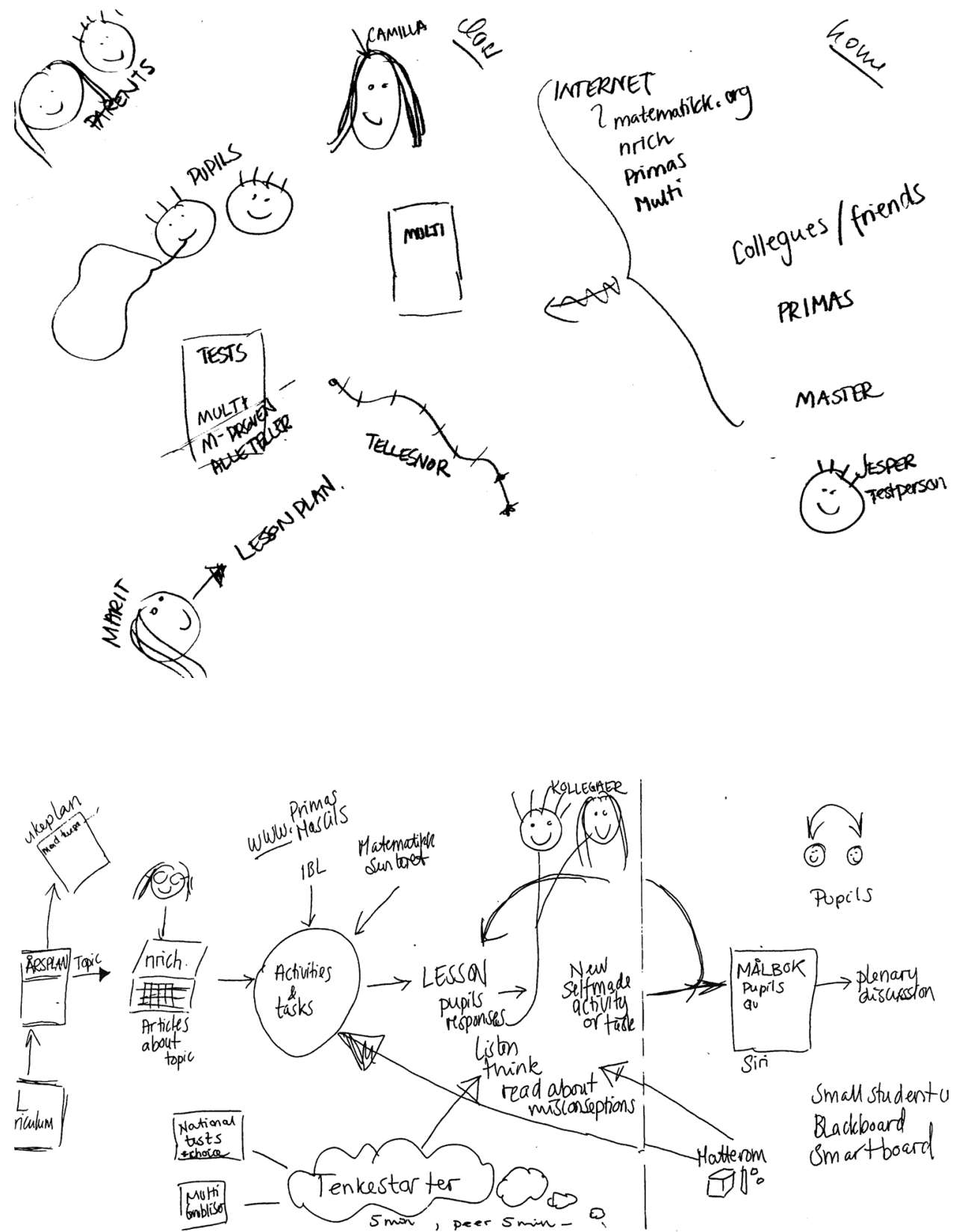

\subsection{Discussion of results on teacher design across the environments and studies}

Drawing on the two design tables, it is clear that mathematics teachers' design has many different facets. For example, different goals appear to necessitate different ways of designing; and different evaluations seem to appeal to different audiences. We could identify the following four dimensions of teachers' design work: 
1. An individual-collective dimension: in the Sésamath environment a collective designers group had been established from the start, which consisted mostly of teachers (with the support of computer specialists). In the PRIMAS environments expert designers and teacher educators designed resources, which were subsequently used by multipliers and teachers engaged in a professional development program. In Vera's case, at first glance her designing was of an individual nature (in her lesson preparations). Nevertheless, we observed that she adapted her teaching according to the students' reactions in class. This 'design-in-use' can thus be seen as a collective design, by Vera and her students. Moreover she was also involved in collective design ('at a distance') with the Sésamath community, and digital resources facilitated this design. Cora also re-designed and adapted the digital PRIMAS tasks, individually for her own lessons, in addition to her (re-) design work on the digital modules with and for her colleagues in her role as multiplier. We note here that the digital PRIMAS resources facilitated collective design in various ways, including collective design by/amongst colleague teachers, teacher educators, and/or researchers. Moreover, the collective design in class by the teacher and her students was also supported by digital tools allowing on-the-spot modifications.

2. A 'narrow to broad' audience dimension: the continuum ranged from designer for/in personal instruction (i.e., Vera and Cora), over design for the PRIMAS multiplier and teacher audience; to designer/s for the public community (i.e., Sésamath e-textbook/chapter designers). Nevertheless, in the case of Sésamath these two extremes often became unclear when teachers developed materials at home and sent in their suggestions for change (of the particular chapter/tasks/activity), which subsequently got implemented-and digital resources afforded this exchange.

3. An approach dimension: ranging from 'single connoisseurship' (e.g., Vera or Cora); over a communicative/ deliberate approach (e.g., platform of ideas, e.g., Sésamath); to a linear/systematic approach (e.g., PRIMAS: from 'expert' to multipliers (and teachers) as 'implementers'). However, due to the digital nature of the curriculum resources the boundaries often became blurred between the approaches: e.g., Vera amended an introductory task in Sésamath and sent it in to the Sésamath association, who in turn approved of it and inserted it into the e-textbook.

4. Quality assurance dimension: ranging from teacher assessment (e.g., Vera or Cora), to collective assessment (e.g., in the case of the Sésamath association), to expert assessment (e.g., PRIMAS professional designers). In both environments (and cases) the opportuni- ties for quality assurance depended to a large extent on the digital nature of the resources: if PRIMAS experts wanted teachers across Europe to trial out the modules and tasks, they had to provide them in digital and adaptable form.

\subsection{Discussion of results in terms of design capacity}

We have refined the notion of teacher design capacity, to consist of three essential aspects, and we have illustrated these aspects in Cora's and Vera's work with digital (and traditional) resources. We observed for both of them a development of their design capacity, stemming in particular from their interactions with digital resources, and their work with/in collectives. Moreover, we evidenced the longterm consistency of selected aspects of their design capacity developed during the design work we observed. We noted in particular the following aspects:

- Whilst Vera's goal was to develop a learning progression for particular topic areas, Cora's goal was to develop IBL practices in her mathematics classroom; yet, their design work yielded professional insights for both of them;

- For both of them, robust design principles guided their design; at the same time new principles were developed, in particular through the interactions with digital resources. Vera searched and found various ways, in a differentiated way, to engage students in the same exercise. This was a consequence of her use of digital resources, namely, the online exercises offered on LaboMEP, which introduced her to the idea of variations of the same exercise. Cora used her insights of IBL to develop her questioning skills (from the PRIMAS module) and in turn her understanding of student thinking. The digital PRIMAS resources provided her with promising examples of how to adapt her questioning skills.

- Both Vera and Cora adapted their designs to the teaching context, in particular through reflection-in-action. This adaptation illustrates what we called design flexibility (flexibility of the design principles allowing adaptation to the context). We claim here that the digital resources (in connection with the professional development) helped teachers to enhance didactical flexibility: by adapting the digital PRIMAS tools for her lessons, Cora developed a flexible way of questioning in order to guide student thinking and to help them to make sense of the proposed activities. Vera observed students' difficulties and modified her 'written trace' accordingly; these observations were possible because of the projec- 
tion on the white board of the digital written trace. We argue that didactical flexibility is a special component of design capacity.

\section{Conclusions}

First, using a lens of teaching as design, this conceptual paper explains (and illustrates) how mathematics teachers' work with digital resources in particular can be regarded as design, and how this design work can enhance mathematics teachers' design capacity. Design capacity is constructed in terms of how teachers understand and transform existing curriculum resources (in this case digital resources) to (re-) design instruction. Leaning on the literature we have (a) conceptualized and refined, and finally (b) illustrated mathematics teacher design and teacher design capacity building in two purposefully selected environments and associated studies of mathematics teachers' interaction with digital (and traditional) resources. Moreover, we claim to have enhanced understandings of the notions of teacher design and design capacity: previous notions of design capacity (e.g., Brown 2009) did not specify (e.g., components) nor illustrate the different aspects of what design capacity might entail. Based on our understanding of teacher interaction with in particular digital resources, we used and elaborated on existing notions of mathematics teacher design, and developed from these the notion of design capacity. This definition now is comprised of three essential components: goal/s of the design activity; a set of principles (robust; and flexible); and reflection-in-action.

Second, regarding the context of our studies, we claim that the European context has offered insights into the use of digital resources and resource systems that are not found in the same way elsewhere: (1) The development of organized collectives of teachers and designers to create, use, revise, and discuss digital materials was different from contexts researched elsewhere; and (2) the development of multi-national efforts to create curriculum resources with the goal of scaling up practices also contributed to research contexts not well-reported elsewhere. Thus, the context of the studies allowed for the study of phenomena that are potentially informative in other countries and may enhance multi-national efforts.

Third, we note that in particular digital resources offer new opportunities for design and design capacity building for teachers, as (1) teachers can participate in a collective design process without actually sitting in the same office/ place (see Sésamath); (2) teachers can differently observe their students and more flexibly adapt the content of their teaching according to their observations (see Vera); and (3) teachers can benefit from a wide range of quality interactive digital resources, some of them designed by specialists (see PRIMAS), which can provide new inspiration and directions for teaching mathematics, as well as insights into designs that are potentially learning enhancing (see Cora). It was evident that the interaction with digital resources was particularly beneficial for teachers working in collectives, as both Sésamath and PRIMAS show. Indeed, it became clear that the affordances of digital curriculum resources not only offer new opportunities, but necessitate different or enhanced teacher design expertise (different from expertise when working with traditional curriculum resources), due to the changing nature of the materials.

Future work is likely to investigate questions about the links between design capacity and Vergnaud's (2013) schemes, in our endeavor to develop deeper insights into mathematics teacher professional knowledge and expertise. Another aspect of further work concerns the design, implementation and evaluation of teacher education programs purposefully built to foster teachers' design capacity.

Open Access This article is distributed under the terms of the Creative Commons Attribution 4.0 International License (http:// creativecommons.org/licenses/by/4.0/), which permits unrestricted use, distribution, and reproduction in any medium, provided you give appropriate credit to the original author(s) and the source, provide a link to the Creative Commons license, and indicate if changes were made.

\section{References}

Adler, J. (2000). Conceptualizing resources as a theme for teacher education. Journal of Mathematics Teacher Education, 3, 205-224.

Brown, M. W. (2009). The teacher-tool relationship: Theorizing the design and use of curriculum materials. In J. T. Remillard, B. A. Herbel-Eisenmann \& G. M. Lloyd (Eds.), Mathematics teachers at work: Connecting curriculum materials and classroom instruction (pp. 17-36). New York: Routledge.

Choppin, J., Carson, C., Borys, Z., Cerosaletti, C., \& Gillis, R. (2014). A typology for analyzing digital curricula in mathematics education. Mathematics, Science and Technology, 2(1), 11-25.

Gueudet, G., Pepin, B., Restrepo, A., Sabra, H., \& Trouche, L. (2017). e-Textbooks and connectivity: proposing an analytical framework. International Journal of Science and Mathematics Education. doi:10.1007/s10763-016-9782-2.

Gueudet, G., Pepin, B., Sabra, H., \& Trouche, L. (2016). Collective design of an e-textbook: Teachers' collective documentation. Journal of Mathematics Teacher Education, 19(2), 187-203.

Gueudet, G., Pepin, B., \& Trouche, L. (Eds.). (2012). From text to 'lived' resources: Mathematics curriculum materials and teacher development. New York, NY: Springer.

Gueudet, G., Pepin, B., \& Trouche, L. (2013). Collective work with resources: An essential dimension for teacher documentation. ZDM, 45(7), 1003-1016.

Huizinga, T. (2009). Op weg naar een instrument voor het meten van docentcompetencies voor het ontwikkelen van curricula [Towards an instrument to measure teacher competencies for the development of curricula]. Enschede: University of Twente.

Huizinga, T., Handelzalts, A., Nieveen, N., \& Voogt, J. (2015). Fostering teachers' design expertise in teacher design teams: 
Conductive design and supportive activities. The Curriculum Journal, 26(1), 137-163.

Jaworski, B. (2001). Developing mathematics teaching: Teachers, teacher-educators and researchers as co-learners. In F. L. Lin \& T. J. Cooney (Eds.), Making sense of mathematics teacher education (pp. 295-320). Dordrecht: Kluwer Academic Publishers.

Jones, K., \& Pepin, B. (2016). Research on mathematics teachers as partners in task design. Journal of Mathematics Teacher Education, 19(2/3), 105-121.

Nieveen, N., \& van der Hoeven, M. (2011). Building the curricular capacity of teachers: Insights from the Netherlands. In P. Picard \& L. Ria (Eds.), Beginning teachers: Challenge for educational systems. CIDREE Yearbook 2011 (pp. 49-64). Lyon: ENS de Lyon, Institut Français de l'Éducation.

Pepin, B., Gueudet, G., \& Trouche, L. (2013). Re-sourcing teacher work and interaction: A collective perspective on resource, their use and transformation. ZDM, 45(7), 929-943.

Pepin, B., Gueudet, G., Yerushalmy, M., Trouche, L., \& Chazan, D. (2015). e-Textbooks in/for teaching and learning mathematics: A disruptive and potentially transformative educational technology. In L. English \& D. Kirshner (Eds.), Handbook of international research in mathematics education (pp. 636-661). New York, NY: Taylor \& Francis

Pepin, B., Xu, B., Trouche, L., \& Wang, C. (2016). Developing a deeper understanding of mathematics teaching expertise: An examination of three Chinese mathematics teachers' resource systems as windows into their work and expertise. Educational Studies in Mathematics, 94(3), 257-274.

Remillard, J., Herbel-Eisenmann, B. A., \& Lloyd, G. M. (Eds.). (2008). Mathematics teachers at work: Connecting curriculum materials and classroom instruction. New York, NY: Routledge.
Remillard, J. T. (2005). Examining key concepts in research on teachers' use of mathematics curricula. Review of Educational Research, 75(2), 211-246.

Sabra, H., \& Trouche, L. (2011). Collective design of an online math textbook: When individual and collective documentation works meet. In M. Pytlak, T. Rowland \& E. Swoboda (Eds.), Proceedings of CERME 7 (pp. 2356-2366). Rzeszów.

Sikko, S. A., Lyngved, R., \& Pepin, B. (2012). Working with mathematics and science teachers on IBL approaches: Teacher concerns. Acta Didaktika Norge, 6(1), 1-18.

Trouche, L. (2004). Managing the complexity of human/machine interactions in computerized learning environments: Guiding students' command process through instrumental orchestrations. International Journal of Computers for Mathematical Learning, 9, 281-307.

Van den Akker, J. (2003). Curriculum perspectives: An introduction. In J. van den Akker, W. Kuiper \& U. Hameyer (Eds.), Curriculum landscapes and trends (pp. 1-10). Dordrecht: Kluwer Academic Publishers.

Vergnaud, G. (2013). Conceptual development and learning. Revista Qurriculum, 26, 39-59 (ISSN: 1130-5371).

Verillon, P., \& Rabardel, P. (1995). Cognition and artifacts: A contribution to the study of thought in relation to instrument activity. European Journal of Psychology in Education, 9(3), 77-101.

Wartofsky, M. W. (1973). Perception, representation, and the forms of action: Toward an historical epistemology. In M. W. Wartofsky (Ed.), Models (pp. 188-210). Dordrecht: D. Reidel Publishing Company. 